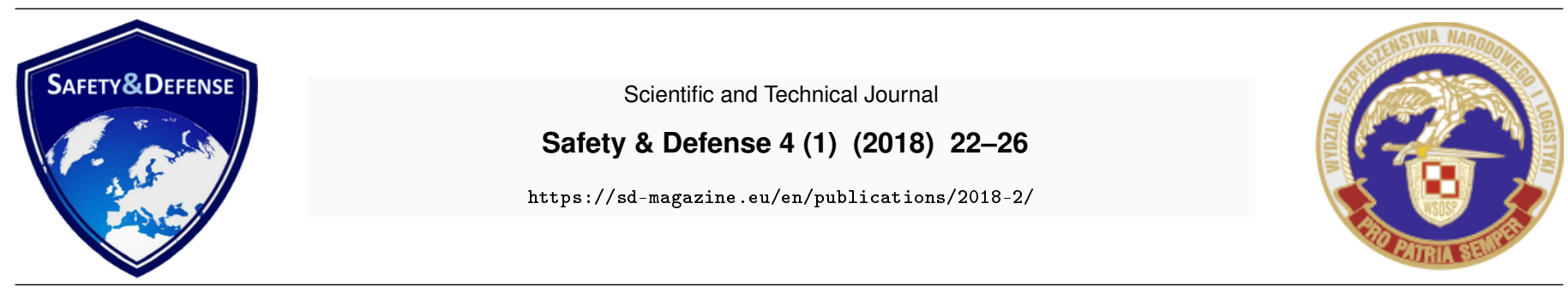

\title{
Capabilities of the Unmanned Aerial Vehicles in Logistic Support
}

\author{
Anna Michalska* \\ National Security and Logistics Faculty, Polish Air Force Academy, ul. Dywizjonu 303 nr 35, 08-521 Dęblin, Poland \\ Katarzyna Karpińska \\ $49^{\text {th }}$ Air Base Pruszcz Gdanski, Powstańców Warszawy 28B, 83-000 Pruszcz Gdański, Poland
}

\begin{abstract}
The main focus of this paper is the capabilities of Unmanned Aerial Vehicles as a military logistic support in conflicts areas. The conducted research addresses the problems of traditional military delivery methods. Next, the problem of using UAVs only for civilian purposes is considered. The paper begins with short elucidation of logistic support and further provides the classification of logistic materials and discusses five categories of military equipment from the logistics point of view. Next, the paper discusses the characteristics of the parameters and properties of the chosen existing UAVs that are used for the delivery of materials. Consequently, a comparison of the UAVs is carried out, and new technologies for logistic transport are presented. This paper is concluded with the claim that it is necessary to modernize the process of logistic support in the military.
\end{abstract}

Keywords: air freight, drones, logistics, logistic support, UAVs, Unmanned Aerial Vehicles

\section{Introduction}

Military logistic support is a component of organizing and realizing supply development. This important aspect has a large impact on the combat capability as well as on carrying out combat operations and keeping troops ready. Moreover, technological changes and the continuing advancement of various types of combat techniques and warfare increase the need for modernisation of logistic (distribution) channels.

Furthermore, the development of logistic supply management and logistic support in the case of armed conflicts should be based on well-worked out and reliable lines of logistic support, i.e. technological and transport support services. These factors are necessary to ensure the successful outcome of any military mission. However, what is also crucial, throughout the realization of the logistic support services during an armed conflict the area is that commanders should not forget about civilians and their needs. Providing assistance to civilians is one of the most important factors that have to be considered during the Military Decision Making Process (MDMP) and it is a part of the CIMIC Civil-

\footnotetext{
* Corresponding author

Email address: a.michalska@ws osp.pl (Anna Michalska)
}

Military Co-operation. On the basis of the analysis of recent military conflicts, a claim can be formulated that during such a conflict civilians may have problems with access to the most basic products such as:

- Foods;

- Hygiene products;

- Medicine products;

- Equipment and materials indispensable for life.

Each of the abovementioned items should be provided by the military to civilians during a battle. However, the proximity to the warfare zone has a direct and negative impact on the safety of transport. In order to provide necessary products, solders, with high probability, will expose themselves to danger by carrying out land transport services. As a result, it is necessary to create a system and methods allowing for the safe and fast transport of goods into a war zone. However, the items can be delivered by Unmanned Aerial Vehicles (UAVs). This new method of logistic support, i.e., with the use of UAVs, has not been yet fully employed by both, the military and civilian transport providers. For military purposes, UAVs have been mostly used to provide intelligence, surveillance, and reconnaissance (ISR) missions, 
which means that there are currently used to examine the topography of a possible/future warzone (either in the air, on the land or the sea) or/and the size of the opponent army. Not only the army uses UAVs for the ISR operations - they are also put to service by civilians organizations who use them, i.e., for:

- Counting the animal population;

- Examining the air pollution levels;

- The needs of the entertainment industry;

- The needs of the cinematic industry.

The analysis carried out in this paper is based on the example of an armed conflict in the form of a hybrid war and the possibility of using the potential of UAVs for logistic support of military actions. The aim of this research is to examine the current practices of employing UAVs as a means of logistic support. That analysis will provide an insight for the main query of the research, namely: How can the army use UAVs in order to increase the efficiency of logistic support in a military conflict area? This research has been conducted with the use of theoretical methods. The direction of the research is determined by the following hypothesis: The enhancement of the existing and developing new UAVs logistic systems is beneficial for handling military conflicts.

\section{The paradigm of logistic support}

Encyclopedia Britannica defines the term "logistics" in the domain of military science as "all the activities of armed-force units in roles supporting combat units, including transport, supply, signal communication, medical aid, and the like". [1] There are, of course, numerous other definitions in literature on the subject. Beier and Rutkowski, for example, describe the term as a process of managing the transport of goods from their places of origin to the place of final consumption". [2] Furthermore, the authors elucidate it in more detail as a "large field of knowledge on the economy and management of the logistic process". [2, own transl.] Taking into consideration the above definitions it may be concluded that logistics support involves all acquisition and logistic processes necessary to provide required items to military units.

It needs to be mentioned here that a number of points in the logistic process, required logistic capabilities and logistic protection services are imposed by NATO, and hence are obligatory in NATO member states. According to the NATO Logistics Handbook, the classes of supply are established in the five-class system of identification:

\section{Class I}

Items of subsistence, e.g. food and forage, which are consumed by personnel or animals at an approximately uniform rate, irrespective of local changes in combat or terrain conditions.

\section{Class II}

Supplies for which allowances are established by tables of organization and equipment, e.g. clothing, weapons, tools, spare parts, and vehicles.

\section{Class III}

Petroleum, oil and lubricants (POL) for all purposes, except for operating aircraft or for use in weapons such as flamethrowers, e.g. gasoline, fuel oil, greases, coal and coke.

\section{Class IIla}

Aviation fuel and lubricants

\section{Class IV}

Supplies for which initial issue allowances are not prescribed by the approved issue tables. This normally includes fortification and construction materials, as well as additional quantities of items identical to those authorized for initial issue (Class II) such as additional vehicles.

\section{Class $V$}

Ammunition, explosives and chemical agents of all types. [3]

The classes mentioned above are included in STANAG 2961 (26.07.2000) that provides a choice criteria for the means of transport. In other words, the type of goods that require transport determines the type of transport we are obliged to use.

An armed conflict, according to the international law, is "any difference arising between two States and leading to the intervention of armed forces is an armed conflict within the meaning of Article 2, even if one of the Parties denies the existence of a state of war. It makes no difference how long the conflict lasts, or how much slaughter takes place". [4] Based on the analysis of this term in literature related to the research carried out, the author will take the definition presented by The International Criminal Tribunal for the former Yugoslavia (ICTY), which proposed a general definition of armed conflict. In the Tadic case, the Tribunal stated that "an armed conflict exists whenever there is a resort to armed force between States". [5]

Furthermore, recent armed conflicts have shown a new kind of war, the so-called hybrid war. The term "hybrid war" rose to prominence in defense and policy circles after the Russian annexation of Crimea in 2014. In its general meaning, hybrid war is "hostile actions that are difficult for a state to identify, attribute or publicly define as coercive uses of force". [6] According to the aforementioned definition, as well as the experiences taken from the war in Ukraine that is a perfect example of such an armed conflict, logistic support of one's own troops is an extremely difficult process while carrying out operations of that type.

Before proceeding to the discussion of the issue of logistic support provided by Unmanned Aerial Vehicles (UAVs), it is 
necessary to properly explain this term. It is also worthwhile to mention that UAVs are very often referred to as "drones," both in specialist literature and common language. Moreover, there are more names for UAVs. Leśnikowski, for example, uses the name "Radio Controlled Aircraft (RCA)". [7]

The Department of Defense of the United States defined a UAV as a "self-flying apparatus, unable to carry the operator, with a possibility of conducting flights independently or remotely, controlled by one or more operators, carrying on board a combat load or not". [8]

Unlike the UAV, the RCA is defined as a "subtype of the UAV, produced commercially or provisional, requiring one operator for the whole period of a remote flight, with the ability of operating in the air for up to 2 hours". [8]

In Poland, the professional term is Unmanned Aerial Vehicle, this term determines an aircraft in airspace and beyond airspace. The term is based on the Polish PN/L-O2501 norm. [7]

In accordance with the analyzed literature, I have defined an UAV and a RCA under one joint definition, namely: UAV or RCA is an aircraft without a human pilot aboard. Its flight is controlled either autonomously by onboard computers or by the remote control of a pilot on the ground or in another vehicle. The typical launch and recovery method of an unmanned aircraft is by the function of an automatic system or an external operator on the ground. [8]

\section{The Characteristic of UAVs}

Traditional logistic delivery methods have become obsolete. Moreover, conducting logistic support during combat may be more hazardous for soldiers' life. On the basis of the current state of affairs in regard to the capability of troops and the need to guarantee them security of the highest possible level, it is important to introduce a new technology with that is characterized by a better capability and quality in order to improve logistic support for the areas under military conflict. Therefore, using automatic systems to execute delivery seems to be a necessary step in military logistics development.

The next step of the analysis is the discussion of the most important tactical and technical capabilities of several selected UAVs. The UAVs that have been chosen are used in military logistic support in different countries.

Based on the literature analysis, I have created a table (Table 1) with tactical and technical data useful in logistic support such as: time flight, range, ceiling and capacity aircrafts. According to this division, there are three different types of UAVs.

To make a final decision as to which group of UAVs should be chosen for logistics, it is important to juxtapose the types of UAVs (Table 1) with the types of transported materials in accordance with military categorization. The typology is presented in Table 2.

On the basis of the data presented in the above tables of UAVs capabilities and materials category, one may draw

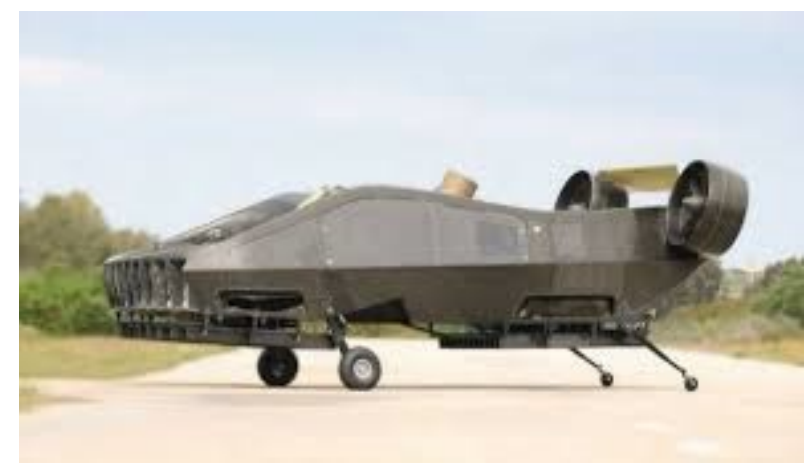

Figure 1: Air Mule (source https://www.electronicspecifier.com/around-theindustry/air-mule-drone-ambulance-makes-first-flight, access: 03/12/2018).

a conclusion that the medium and high types of drones are the most suitable for logistic support. The next step of the analysis is to present a detail characteristic of several chosen UAVs from these groups (medium and high), which will serve as a case study examination.

One of the common UAVs used by military is AirMule. This UAV has been constructed and developed by Israel in order to indemnify Lebanon aid during a military conflict. The safe design of AirMule makes it very user-friendly and does not pose a threat for people who come into close contact with it. According to tactical and technical data "it can operate in bad weather and stay in hover with winds of up to $50 \mathrm{kn}(93 \mathrm{~km} / \mathrm{h})$. AirMule has an autonomy of about two hours and can fly on a ceiling of up to $3,600 \mathrm{~m}$. It is able to deliver $500 \mathrm{~kg}$ at a distance of up to $50 \mathrm{~km}$ ". [9] Its advanced technical position and control systems allow for safe flight, and in the case of danger or failure, for safe compliancy on the ground.

The next UAV which will be described is K-Max. It is important to point out that this UAV is an optional vehicle. It means that this UAV can be controlled by remote panel autonomically or with the use of traditional method of pilotage. K-Max was used in the military mission in Afghanistan. The efficiency of this UAV was tested in difficult weather conditions. The majority of the task carried out by this UAV were amphibious operation. [9] K-Max is an UAV with high lifting capacity and high stability of hovering. It can conduct a combat task at a distance of $556 \mathrm{~km}$ with a load of $2721 \mathrm{~kg}$ at sea level and $1814 \mathrm{~kg}$ at the level $4572 \mathrm{~m}$. [10]

The last UAV discussed in this paper is the Camcopter S-100 developed by Austrian constructors. The Comcopter S-100 is equipment with a modernized flight planning, control, and capacity control systems. Additionally, it is able to analyze the threatened areas with the use of navigation systems. Camcopter S-100 is able to carry out tasks in the area of $180 \mathrm{~km}$ (6 hours of work) with a lifting capacity of $34 \mathrm{~kg}$. [9] The UAV is used by countries such as the United Arab Emirates, China, Italy, Russia, and some of NATO member countries.

In spite of great usefulness of the above described UAVs, only a small number of countries employ them for logistic operations. There are no doubts that introducing that type of 
Table 1: Types of UAVs

\begin{tabular}{lllrr}
\hline Groups & Time flight, $\mathrm{h}$ & Range, $\mathrm{km}$ & Ceiling, $\mathrm{m}$ & Capacity, kg \\
\hline LOW & $<5$ & $<100$ & $<1,000$ & $<50$ \\
MEDIUM & $5-24$ & $100-400$ & $1,000-10,000$ & $50-100$ \\
HIGH & $>24$ & $>1,500$ & $>10,000$ & $>100$ \\
\hline
\end{tabular}

Table 2: Types of Transported Materials

\begin{tabular}{lrrr}
\hline Category & Materials & Quantity & Mass \\
\hline I & Polish food ration SRG* & 1 item & $\approx 2 \mathrm{~kg}$ \\
II & Polish hel Kevlar model 2005 r. & 100 items & $\approx 100 \mathrm{~kg}$ \\
III & Desulphated Molybdian (grease) & - & $100 \mathrm{~kg}$ \\
IIIA & Castrol 599 (oil) or Turbomycin 699 (oil) & - & 100 I \\
IV & Barbed wire 2,5 mm & $2,400 \mathrm{~m}$ & $\approx 240 \mathrm{~kg}$ \\
V & Assault rifle, model 96 BERYL version "C" with full magazine & 1 item & $4.204 \mathrm{~kg}$
\end{tabular}

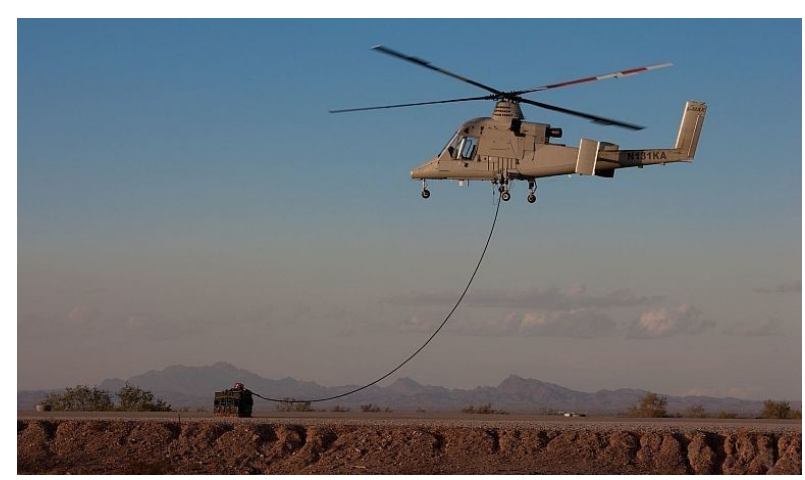

Figure 2: K-Max (source: http://www.defence24.pl/sily-zbrojne/dron-k-maxz-systemem-samodzielnego-podnoszenia-ladunkow, access: 03/12/2018).

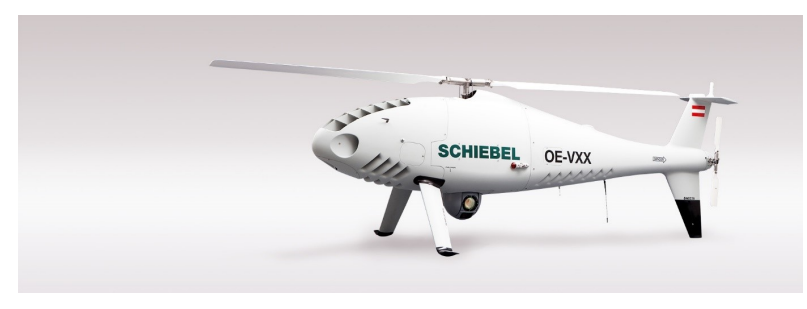

Figure 3: Camcopter S-100 (source: https://schiebel.net/ products/camcopter-s-100-system-2/ access: 03/12/2018).

equipment into military transport operations will bring forth many advantages - such drones would permit carrying out safer, quicker, and more convenient logistic support services.

\section{Conclusion}

Taking all the above facts and arguments into consideration, it has to be stated that transporting materials with the use of UAVs will have a positive effect on the performance of combat missions. Moreover, it will improve the system of logistic supply for military units during an armed conflict. The will to employ UAVs as a transport means has also con- tributed to the development of the civilian market. The reported cases of attempts of using that kind of equipment by delivery companies like DHL reveals a broad interest in this method of transporting goods. DHL has not yet used UAVs as a logistic transport method to deliver packages due to technical difficulties. However, as DHL has announced, once they finally deal with them, they will make a decision about the location of small and medium packets delivery. [11]

The carried out analysis demonstrates that the technologies and supply methods for military units currently used during an armed are not sufficient. As shown in the discussion, there are few vital UAVs' parameters, which play a significant role in choosing the adequate drone for a particular material delivery. Another group of criteria that have to be taken into account during this decision process are technical capabilities. The latter should serve as a guideline for the optimal parameterization and selection which UAV could fulfill the individual requirements of a certain type of mission.

One of the main points of this paper is the research supported statement that the existing military logistics supply systems are not sufficiently using new technologies. Analyzing the outdated methods of logistic support employing the traditional transport means in the context of the existing threats of military conflicts forces us to implement new methods, where UAVs are one of them. This solution enables the safe displacement of materials with fewer threats of losing the cargo and human life. Moreover, transportation drones may be used by European countries to provide the necessary aid for civilians.

\section{References}

[1] R. M. Leighton, Logistics., In Encyclopaedia Britannica., retrieved from: (12.03.2018) (2018).

URL https: //www.britannica.com/topic/logistics-military

[2] F. J. Beier, K. Rutkowski, Logistyka., Warszawa: Szkoła Główna Handlowa. (1995).

[3] NATO Logistics Handbook., Senior NATO Logisticians' Conference Secretariat, Annex A, 3rd ed. Brussels: NATO Headquarters. (1997). 
[4] J. Pictet, Commentary on the Geneva Convention for the Amelioration of the Condition of the Wounded and Sick in Armed Forces in the Field, ICRC (1952).

[5] ICTY, The Prosecutor v. Dusko Tadic, Decision on the Defence Motion for Interlocutory Appeal on Jurisdiction, IT-94-1-A, 2, para. 70 (1995).

[6] A. Mumford, J. McDonald, Ambiguous Warfare., Report produced for the DCDC. (2014).

[7] W. Leśnikowski, Drony bezzałogowe aparaty latające od starożytności do współczesności., Toruń: Bellona. (2016).

[8] D. Michalski, A. Michalska, Protection against Drone Activity., Security Forum 1 (2017) 73-83.

[9] M. J. Dougherty, Drony ilustrowany przewodnik po bezzałogowych pojazdach powietrznych i podwodnych., Warszawa: Bellona. (2016).

[10] Army Recognition, K-MAX Lockheed Martin Unmanned helicopter., retrieved from: (12.03.2018) (2010).

URL https: //www . armyrecognition. com/us_american_unmanned _aerial_ground_vehicle_uk/k-max_kaman_lockheed_mart in -unmanned_aerial_vehicle_uav_drone_data_sheet specifications_information.html

[11] $\bar{M}$. Połowianiuk, DHL Company. Spider's Web., retrieved from: (03/12/2018) (2016).

URL https://www.spidersweb.pl/2016/01/dron-kurier-dhl -paketkopter-3-0.html 